\section{Primary tongue tuberculosis: a case report}

\section{Kafle SU, ${ }^{*}$ Upadhyaya $P,{ }^{1}$ Sinha AK,1 Karki S, ${ }^{1}$ Pradhan A, ${ }^{1}$ Paudyal P,1 Agarwal M,1 Bhandary $\mathbf{S}^{2}$}

${ }^{1}$ Department of Pathology, B. P. Koirala Institute of Health Sciences, Dharan, Nepal; ${ }^{2}$ Department of Otolaryngology and Head and Neck Surgery, B. P. Koirala Institute of Health Sciences, Dharan, Nepal

*Corresponding to: Dr. Santosh Upadhyaya Kafle, Department of Pathology, B. P. Koirala Institute of Health Sciences, Dharan, Nepal, email: santoshupadhyaya.kafle@bpkihs.edu, Tel. No.: (+977)-9852028480

\section{ABSTRACT}

INTRODUCTION: Tuberculosis of the tongue is one of the less common lesions caused by the mycobacterium bacilli whether primary or secondary. Most of the reported cases in the literature are in association with pulmonary lesion or a primary focus elsewhere.

CASE REPORT: We report a case of 63 years old male patient from Rajghat, Morang, Nepal with burning sensation over tongue since 30 days. Microscopic examination revealed epithelioid cell granuloma, caseous necrosis and Langhans giant cell with Acid Fast Bacilli on Ziehl Neelsen staining.

CONCLUSION: Lingual Tuberculosis is a diagnostic dilemma because of its rarity. Hence, we are reporting this case.

KEY WORDS: Mycobacterium, Lingual, Dilemma

Article submitted 20 February. Reviewed 10 March. Author correction 15 March. Final version accepted 20 March 2013. 


\section{INTRODUCTION}

Tuberculosis is an infectious, chronic granulomatous disease that can involve almost any organ in the body, but primary lesions are usually confined to the lungs. Oral lesions are an infrequent occurrence in tuberculosis, and tuberculosis of the oral cavity is often a consequence of active pulmonary tuberculosis. Although primary tuberculosis in the oral cavity has been documented, it is a rare occurrence. ${ }^{1}$ It is reported to have an incidence rate of 1.4 to $2 \%$. It can occur as the only manifestation or in conjunction with pulmonary or extra pulmonary tuberculosis. Morgagni described the first case of Lingual tuberculosis in the year $1761 .^{2}$ Since the tongue of every patient with the active tuberculosis is exposed to positive sputum, the relative infrequency of tuberculosis must be explained. It is probably due to combination of the reasons like, the thickness of mucous membrane, the resistance of the striated muscle of tuberculosis, the cleansing action of saliva, and the well-nigh perpetual motion of the tongue. ${ }^{3}$

There have been isolated case reports in the literature. $4,5,6,7,8$ Most of the reported cases in the literature are in association with pulmonary lesion or a primary focus elsewhere. Often the clinical presentation may pose diagnostic difficulties. It is rare to suspect a nodule or ulcer in the tongue to be tuberculous on clinical examination. More often the diagnosis is made after histopathological examination of the lesion.

We are reporting a rare case of primary tuberculosis of tongue in a 63 years old male diagnosed in a histopathological examination with a positive Acid Fast Bacilli (AFB) in Ziehl Neelsen (ZN) stain.

\section{CASE REPORT}

A 63 years old male, farmer from Rajghat, Morang, Nepal presented with complaints of burning sensation over the tongue for past 30 days. There was no history of cough, fever, hemoptysis and significant weight loss. He was average built with habit of smoking and chewing tobacco since 30 years. Examination revealed $2 \times 2 \mathrm{~cm}^{2}$ friable, nontender, fixed, grey white to grey brown mass with indurated surrounding tissue on the posterior part of dorsal surface of tongue. No lymphadenopathy or organomegaly was found. Chest X-ray was normal with a clinical diagnosis of malignancy.
Histopathological examination from initial biopsy revealed nonspecific inflammation. Microscopy from repeat biopsy showed multiple epithelioid cell granulomas, Langhans giant cells with caseous necrosis (Photographs 1 and 2). ZN stain for AFB (Photograph 3) was positive and proved primary tuberculosis of tongue. Anti-tubercular therapy for nine months showed uneventful recovery of patient.

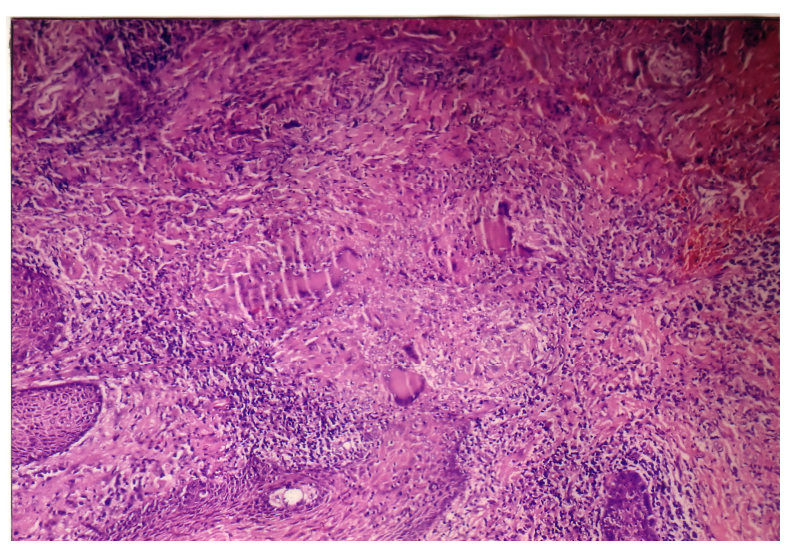

Photograph 1. Showing stratified squamous lining epithelium along with Langhans' type of gaint cells in subepithelium (H\&E x100)

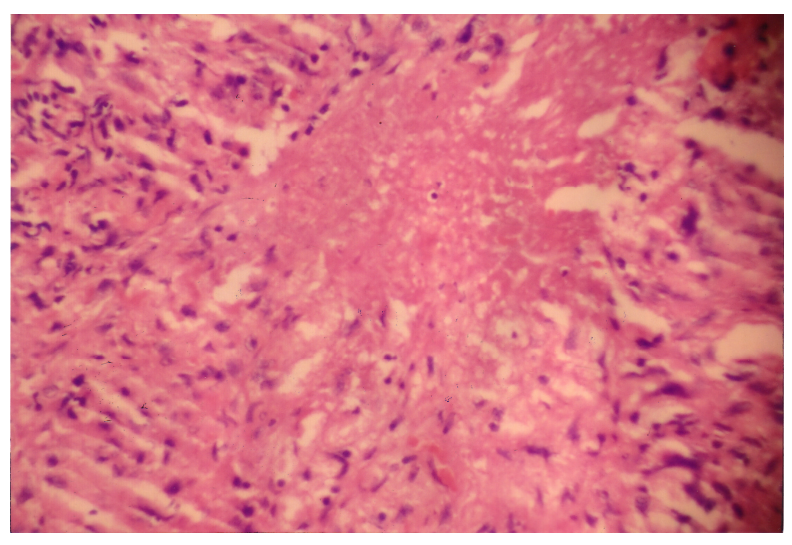

Photograph 2. Showing epitheliod cell granuloma with central caseous necrosis (H\&E stain x400)

\section{DISCUSSION}

Primary tuberculosis of oral cavity including tongue is very rare. It has been suggested that tongue involvement usually occurs due to contact with the infected sputum or by blood spread, or by direct contamination from the neighboring tuberculous focus in the oral cavity. A breach in the mucosa due to any reason is one of the important predisposing factors. ${ }^{4}$ 


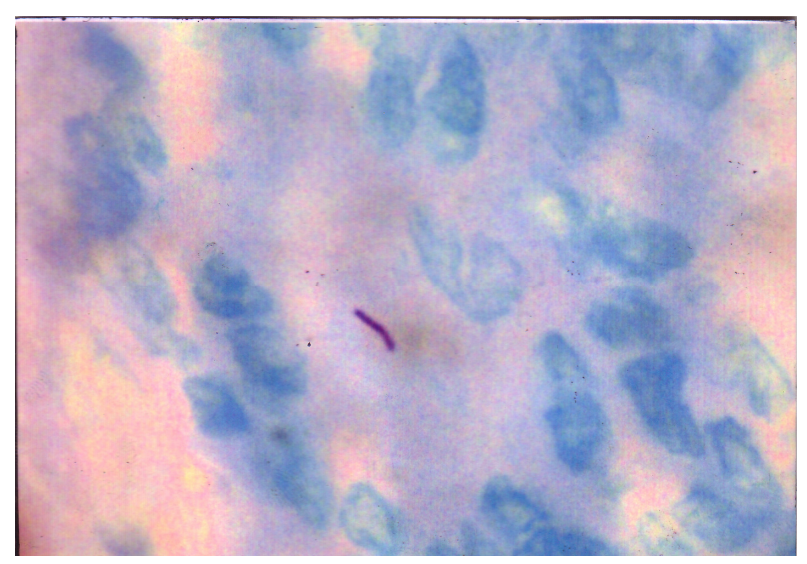

Photograph 3. Showing Acid Fast Bacilli (Z-N stain $\mathrm{x} 1000$ )

Weaver reported that $1-1.5 \%$ cases of pulmonary tuberculosis show tuberculosis of oral cavity, the sites most frequently affected are tongue, palate, tonsil, pharynx, and buccal mucosa ${ }^{5}$. Nagar et al. also reported a case of primary tuberculosis of palate ${ }^{6}$. Panek et al. described a case of tuberculosis of tongue associated with pulmonary lesion, diagnosed by thin-needle biopsy7 ${ }^{7}$. Identification of AFB by ZN stain is confirmatory, but this is frequently negative in tissue sections. 6,8

The diagnosis thus rests on finding the typical granulomas and caseation necrosis of tuberculosis. In some cases, the diagnosis of lingual tuberculosis resulted in the detection of pulmonary lesion which is interpreted as blood-stream dissemination. Memon et. al. also found a case of primary lingual tuberculosis which was diagnosed histopathologically after a second biopsy, the initial biopsy report was nonspecific inflammation. ${ }^{8,9,10}$

We believe this case to be primary tuberculosis of the tongue as we could not detect any other primary focus. Oral tuberculous lesions may take the form of nodules, ulcers, and elevated fissures. Ulcers are irregular with undermined edges, are painful and increase slowly. ${ }^{11}$ Clinically, the diagnosis of oral tuberculosis is not possible and histopathology provides a reliable diagnostic clue as in this case. Further, the Mycobacterium was confirmed by detection of AFB in ZN stain. It is to be differentiated from nonspecific ulcerative lesions, traumatic lesions, and early malignant lesions.

\section{CONCLUSION}

Clinically, the diagnosis of Lingual Tuberculosis is possible and histopathology provides a reliable diagnostic clue as in this case. We need to be aware of this condition for early diagnosis and treatment.

CONFLICT OF INTEREST: None to declare.

FINANCIAL INTEREST: None to declare.

\section{REFERENCES}

1. Garg RK, Singhal P. Primary tuberculosis of the tongue: a case report. J Contemp Dent Pract 2007;1;8:7480.

2. Morgagni G. De sedibus et causis morborum per anatomen indigatis_libri quinque: Dissectiones, et animadversiones nune primum editas complectuntur. $1^{\text {st }}$ ed. SI 1779. lib.5,444.

3. Titche LL. Tuberculosis of the tongue. Am Rev Tuberc 1945;52:342.

4. Ghose SM. Ulcers of tongue. J Indian Med Assoc 1966;41:377.

5. Weaver RA. Tuberculosis of tongue. J Am Med Assoc 1976;235:2418.

6. Nagar RC, Joshi CP, Kanwar DL. Tuberculosis of oral cavity. Ind J Tuber 1985;32:158-1589.

7. Panek B, Chyczewska E, Miroz RM. Tuberculosis of the tongue. Pneumonol Largo Pol 1999;67:477-480.

8. Aguirre GF, Fuertes MA, Guillın Guerrero VS, et al. Tongue tuberculosis as the first expression of the lung process. An Otorrinolaringol Iberno Am 2000;27:111-118. 9. Weichselbaumer W, Schmid E. Tuberculosis of tongue. Laryngol Rhinol Otol (Stuttg) 1976;55:726-729.

10. Memon GA, Khushk IA. Primary tuberculosis of tongue. J Coll Physicians Surg Pak 2003;13:604-605.

11. McAndrew PO, Adekeye EO, Ajdukiewicz AB. Miliary tuberculosis presenting with multi-focal oral lesions. $\mathrm{Br}$ Med J 1976;1:1320.

\section{Citing this article}

Kafle SU, Upadhyaya P, Sinha AK, et al. Primary tongue tuberculosis: a case report. Int J Infect Microbial 2013;2(1);26-28. 